\title{
AS COMPETÊNCIAS DO PROFISSIONAL DE SECRETARIADO NA IMPLANTAÇÃO DE PROJETOS SUSTENTÁVEIS
}

\section{THE SKILLS OF THE PROFESSIONAL SECRETARIAT IN IMPLEMENTING SUSTAINABLE PROJECTS}

\section{Maria do Carmo Assis Todorov}

Mestranda do Programa de Mestrado Profissional em Administração - Gestão de Projetos da Universidade Nove de Julho - PMPA-GP/UNINOVE

E-mail: madu@sinsesp.com.br (Brasil)

\section{Claudia Terezinha Kniess}

Doutora em Ciência e Engenharia de Materiais pela Universidade Federal de Santa Catarina UFSC

Professora do Programa de Mestrado Profissional em Administração - Gestão de Projetos da Universidade Nove de Julho - PMPA-GP/UNINOVE

E-mail: ctkniess@ uninove.br (Brasil)

\section{Marcírio Silveira Chaves}

Doutor em Informática pela Universidade de Lisboa, Portugal

Professor do Programa de Mestrado Profissional em Administração - Gestão de Projetos da Universidade Nove de Julho - PMPA-GP/UNINOVE

E-mail: mschaves@uninove.br (Brasil) 
As competências do profissional de secretariado na implantação de projetos sustentáveis

\title{
AS COMPETÊNCIAS DO PROFISSIONAL DE SECRETARIADO NA IMPLANTAÇÃO DE PROJETOS SUSTENTÁVEIS
}

\section{RESUMO}

Desde a década de 1990, o tema da sustentabilidade passou a incorporar com mais intensidade o mundo dos negócios (Barbieri, Vasconcelos, Andreassi, \& Vasconcelos, 2010). Nesse sentido, o gerenciamento de projetos precisou levar em conta a sustentabilidade, em suas três dimensões: econômica, ambiental e social (Carvalho \& Rabechini Jr, 2011). O gerenciamento de projetos sustentáveis também cresceu nas últimas décadas, exigindo profissionais que contribuam para o sucesso destes projetos (Souza, 1993). Diante deste cenário, este trabalho busca responder a seguinte questão: Quais as competências do profissional de secretariado na implantação de projetos sustentáveis? O objetivo do trabalho é identificar as competências do profissional de secretariado na implantação de projetos sustentáveis, por meio de uma pesquisa qualitativa e exploratória. As competências apresentadas pelos 206 respondentes compatíveis com as competências da sustentabilidade são: gerenciamento de informações, assegurando uniformidade e referencial para diferentes usuários; habilidade de lidar com modelos inovadores de gestão; adoção de meios alternativos relacionados com a melhoria da qualidade e da produtividade dos serviços; abertura às mudanças, iniciativa, criatividade, determinação, vontade de aprender; consciência das implicações e responsabilidades éticas e utilização do raciocínio lógico, crítico e analítico; domínio dos recursos de expressão e de comunicação, inclusive nos processos de negociação e nas comunicações interpessoais ou intergrupais.

Palavras-chave: Competências; Secretariado; Projetos Sustentáveis.

\section{THE SKILLS OF THE PROFESSIONAL SECRETARIAT IN IMPLEMENTING SUSTAINABLE PROJECTS}

\begin{abstract}
Since the 1990s, the subject of Sustainability started to be incorporated more intensely in the business world (Barbieri, Vasconcelos, Andreassi, \& Vasconcelos, 2010). Accordingly, the project management had to take into account sustainability in its three dimensions: economic, environmental and social ones (Carvalho \& Rabechini Jr, 2011). The management of sustainable projects has also grown in recent decades, requiring professionals who contribute to the success of these projects (Souza, 1993). In this scenery, this paper seeks to answer: What are the skills of a secretariat professional for implementing sustainable projects? The objective is to identify the skills of professional secretariat in implementing sustainable projects, through a qualitative exploratory survey. The skills displayed by the 206 respondents compatible with the skills of sustainability are: information management, ensuring uniformity and reference for different users, the ability to deal with innovative business models; adoption of alternative means related to improving the quality and productivity services; openness to change, initiative, creativity, determination, willingness to learn; awareness of the implications and ethical responsibilities and the use of logical, critical and analytical thinking; domain resources of expression and communication, even in negotiation processes and in interpersonal communication.
\end{abstract}

Keywords: Skills; Secretariat; Sustainable Projects.

Revista de Gestão e Secretariado - GeSec, São Paulo, v. 4, n. 3, p 189-209, dez. 2013. 


\section{INTRODUÇÃO}

As atividades de uma organização podem ser divididas em duas categorias: operações e projetos. As operações são as atividades que repetem como o serviço e produção. Já os projetos estão ligados a inovação, novos produtos, novas organizações e novas iniciativas. O projeto pode ser definido como um empreendimento ou esforço temporário - com começo e fím definido - e único, envolvendo incerteza e complexidade, que requer um gerenciamento flexível e ajustável (Shenhar \& Dvir, 2010).

As grandes mudanças que aconteceram no mercado de trabalho nas últimas décadas, buscando vantagem competitiva, resultaram na consolidação do gerenciamento de projetos e a importância em desenvolver competências, levando a um crescimento na formação de profissionais especializados em gestão de projetos (Carvalho \& Rabechini Jr, 2011).

Desde a década de 1990, o tema da sustentabilidade passou a incorporar com mais intensidade o mundo dos negócios (Barbieri, Vasconcelos, Andreassi, \& Vasconcelos, 2010). Nesse sentido, o gerenciamento de projetos precisou levar em conta a sustentabilidade, em suas três dimensões: econômica, ambiental e social (Carvalho \& Rabechini Jr., 2011). Segundo Martens, Brones, e Carvalho (2013), o tema sustentabilidade, aplicado em projetos de diversas naturezas, constitui um grande desafio, podendo ser tema relevante em diversas pesquisas.

O gerenciamento de projetos sustentáveis também cresceu nas últimas décadas, exigindo profissionais que contribuam para o sucesso destes projetos (Souza, 1993). Porém, em relatório recente, o Brasil ocupa o 45․ lugar no ranking de Sustentabilidade (RobecoSAM, 2013). O Ranking de Sustentabilidade RobecoSAM é constituído por 17 indicadores que avaliam fatores ambientais, sociais e de governança corporativa e seu resultado mostra a investidores riscos e oportunidades de cada país. O engajamento de líderes, colaboradores e demais stakeholders em projetos sustentáveis pode contribuir na conquista da vantagem competitiva (Brito \& Berardi, 2010).

O Secretariado Executivo se insere nesse contexto, pois exerce suas atribuições de maneira integrada aos demais e assume o papel de cogestor, mostrando-se proativo, com capacidade de liderança quando da ausência de um superior hierárquico (Adelino \& Silva, 2012), podendo engajar-se em projetos sustentáveis. Segundo Bruno (2006), o profissional de Secretariado trabalha em uma posição estratégica, transformando dado em informação estruturada. Para Halice, Yilmaz, e Kasimoğlu (2012), os profissionais de Secretariado, além de conhecerem a área de negócios dos seus gerentes, desempenham um importante papel na comunicação, tornando-se elementos fundamentais na administração.

Revista de Gestão e Secretariado - GeSec, São Paulo, v. 4, n. 3, p 189-209, dez. 2013. 
As competências do profissional de secretariado na implantação de projetos sustentáveis

Como comunicação é um dos fatores críticos de sucesso na Gestão de Projetos (Carvalho \& Rabechini, 2011), entre outros, o profissional de secretariado pode ser um aliado no gerenciamento de projetos em geral e especificamente em projetos sustentáveis.

Diante desse cenário, este trabalho busca responder a seguinte questão de pesquisa: Quais as competências do profissional de secretariado na implantação de projetos sustentáveis? Nesse sentido, o objetivo do trabalho é identificar as competências do profissional de secretariado na implantação de projetos sustentáveis.

Este trabalho está estruturado em cinco seções. Na primeira seção, nesta introdução, é apresentado o problema de pesquisa e seu objetivo. Na segunda seção, a revisão teórica dos polos: Gerenciamento de Projetos, Projetos Sustentáveis e Competências do Profissional de Secretariado. $\mathrm{Na}$ terceira seção, é apresentada a metodologia de pesquisa. A seção seguinte mostra os resultados da pesquisa. Por fim, na conclusão, são apresentadas as principais contribuições do estudo, limitações e sugestões de estudos futuros.

\section{REFERENCIAL TEÓRICO}

Este trabalho pretende discutir os seguintes tópicos: gerenciamento de projetos, projetos sustentáveis e competências do profissional de Secretariado na implantação de projetos sustentáveis.

\subsection{GERENCIAMENTO DE PROJETOS}

Um projeto é um esforço temporário, com início e término definidos, empreendido para criar um produto, serviço ou resultado exclusivo, aplicando conhecimento, ferramentas e técnicas para atender aos seus requisitos, como prazo, custo, entre outros (PMI, 2008; Maximiano, 2002). O gerenciamento de projetos pode ser definido como planejar, programar e controlar uma série de tarefas integradas (Kerzner, 2006), que objetivam atender ou superar as necessidades e expectativas dos stakeholders (Carvalho \& Rabechini Jr, 2006).

Segundo autores como Shenhar e Dvir (2010); Carvalho e Rabechini Jr. (2011) e Kerzner (2011), foi na década de 1990 que o gerenciamento de projetos se consolidou e de uma forma estruturada passou a ser adotado por empresas do mundo inteiro.

O gerenciamento de projetos tem cinco fases: a) Fase de definição: é a fase inicial do 
projeto. Nela, a missão e o objetivo do projeto são definidos; b) Fase de planejamento: é responsável por identificar e selecionar as melhores estratégias de abordagem do projeto, detalhando tudo aquilo que será realizado; c) Fase de execução: é quando se materializa tudo aquilo que foi planejado anteriormente. Qualquer erro cometido nas fases anteriores fica evidente durante essa etapa. Grande parte do orçamento e do esforço do projeto é consumida nesta fase; d) Fase de controle: é a que acontece paralelamente ao planejamento operacional e à execução do projeto. Tem como objetivo acompanhar e controlar aquilo que está sendo realizado pelo projeto de modo a propor ações corretivas e preventivas, no mínimo espaço de tempo possível, após a detecção da anormalidade; e) Fase de finalização: é quando a execução dos trabalhos é avaliada por auditoria interna ou externa (terceiros) (PMI, 2008).

O Guia do conhecimento em gerenciamento de projetos (PMBOK) é referência básica para o gerenciamento de projetos (PMI, 2012). Nele eram encontradas as nove áreas do conhecimento, que agrupam atividades e tarefas. Em sua quinta edição, o PMBOK contempla a décima área do conhecimento: "partes interessadas” (stakeholders) (PMI, 2012), conforme Quadro 1.

\begin{tabular}{|c|c|}
\hline ÁREAS & CARACTERÍSTICAS \\
\hline Integração & $\begin{array}{l}\text { Subconjunto do gerenciamento de projetos que engloba os processos requeridos para assegurar } \\
\text { que todos os elementos do projeto sejam adequadamente coordenados. }\end{array}$ \\
\hline Escopo & Engloba todo o trabalho que deve ser feito com a finalidade de entregar o produto/serviço final. \\
\hline Tempo & $\begin{array}{l}\text { Define o sequenciamento das atividades; estimativa de recursos; a duração das atividades; o } \\
\text { desenvolvimento; o plano de trabalho e o controle do cronograma. }\end{array}$ \\
\hline Custo & Estima os custos; a orçamentação; e o controle de custos. \\
\hline Qualidade & $\begin{array}{l}\text { São definidos os processos que garantam que o projeto atingirá os objetivos definidos no } \\
\text { escopo. Com os processos é possível realizar o planejamento e o controle para a garantia da } \\
\text { qualidade. }\end{array}$ \\
\hline $\begin{array}{l}\text { Recursos } \\
\text { Humanos }\end{array}$ & $\begin{array}{l}\text { Criação do gerenciamento de pessoal, com a definição de papéis; identificação e documentação } \\
\text { de funções; atribuição de responsabilidades e das relações hierárquicas no projeto. }\end{array}$ \\
\hline Comunicações & $\begin{array}{l}\text { Aplicação das ferramentas de comunicação existentes para divulgação do projeto, ações e } \\
\text { futuros resultados. }\end{array}$ \\
\hline
\end{tabular}


As competências do profissional de secretariado na implantação de projetos sustentáveis

\begin{tabular}{|c|l|}
\hline ÁREAS & \multicolumn{1}{c|}{ CARACTERÍSTICAS } \\
\hline Risco & $\begin{array}{l}\text { Identificar no projeto eventos ou condições que poderão ter efeito de incertezas positivas ou } \\
\text { negativas seja no escopo, prazo ou custo do projeto. }\end{array}$ \\
\hline Aquisições & $\begin{array}{l}\text { Utilizado para garantir ao projeto que todo elemento externo participante irá garantir o } \\
\text { fornecimento de seu produto ou serviço. }\end{array}$ \\
\hline $\begin{array}{c}\text { Partes } \\
\text { Interessadas }\end{array}$ & Identificar as partes interessadas. \\
\hline
\end{tabular}

Quadro 1- Áreas do Conhecimento baseados no PMBOK (2012).

Fonte: Adaptado PMI (2012).

Segundo Valle, Soares, Finocchio, e Silva (2007), para o gerenciamento de projetos é preciso conciliar o trabalho de diferentes pessoas e um dos fatores críticos de sucesso do gerenciamento de projetos está nas competências dos envolvidos. As competências de um profissional estão baseadas em três propriedades básicas que geram as competências em gerenciamento de projetos: competências individuais, competências de equipe e competências da organização (Frame, 1999).

Carvalho e Rabechini Jr. (2011, p. 376) definem as competências individuais como sendo as “aptidões e habilidades dos indivíduos na solução de problemas". As competências de equipe estão voltadas para resolução de problemas complexos e as competências da organização estão na "capacidade de criação de um ambiente que possibilite o envolvimento tanto do indivíduo quanto das equipes, a tocarem seus projetos de forma eficaz".

Thamhain (2012) defende que o ambiente organizacional está passando por rápidas mudanças globais e o gerenciamento de projetos executa operações de negócios multidisciplinares que podem apresentar resultados melhores, com menor custo e prazo quando integra uma equipe de pessoas envolvidas e em sintonia, fomentam um clima de participação ativa, responsabilidade e orientação para o resultado.

\subsection{PROJETOS SUSTENTÁVEIS}

O termo desenvolvimento sustentável diz respeito a utilização de recursos necessários à geração presente sem comprometer as gerações futuras (WCED, 1987). A literatura apresenta várias definições sobre desenvolvimento sustentável, mas há consenso de que há pelo menos três pilares:

Revista de Gestão e Secretariado - GeSec, São Paulo, v. 4, n. 3, p 189-209, dez. 2013. 
econômico, ambiental e social, também conhecidos como Triple Botom Line (Elkington, 2001).

Já a definição de sustentabilidade, muitas vezes definida como desenvolvimento sustentável, não é sinônimo. Para Souza (2010, p. 35), “enquanto a sustentabilidade refere-se à capacidade de manter algo em um estado contínuo, o desenvolvimento sustentável envolve processos integrativos que buscam manter o balanceamento dinâmico de um sistema complexo em longo prazo”. Munck e Borim-de-Souza (2009) corroboram com esta discussão e acrescentam que o desenvolvimento sustentável e a sustentabilidade buscam os mesmos objetivos, porém o primeiro promove o segundo.

Nos documentos oficiais que apresentam a discussão e as orientações sobre o desenvolvimento sustentável destaca-se o Relatório Brundtland (WCED, 1987), documento intitulado como "Nosso Futuro Comum". O Relatório Brundtland foi elaborado pela Comissão Mundial sobre Meio Ambiente e Desenvolvimento (CMMAD) ou em inglês World Commission on Environment and Development (WCED). Em 1992, durante a Rio-92, foram assinados alguns documentos como a Carta da Terra e a Agenda 21 (Barbieri, 2010).

Em um levantamento bibliométrico realizado por Martens, Brones, e Carvalho (2013), 43\% dos artigos avaliados conceituam sustentabilidade pelo Triple Botom Line, 39,1\% pelo conceito ambiental e os 17,4\% restantes se dividiram em conceitos econômico/ambiental, agenda 21 e multistakeholder.

Segundo Munck (2013), o conceito de desenvolvimento sustentável, pode ser dividido em dois grupos de informação e análise. O grupo dos cientistas, técnicos de governo e políticos e o grupo dos organismos e das entidades internacionais de fomento na área de meio ambiente.

Dentro de tal contexto, a nova ideia de desenvolvimento econômico teria de englobar os elementos econômico, social e ambiental. Claro, Claro, e Amâncio (2008) constataram que as práticas gerenciais econômicas atrasam o entendimento do termo sustentabilidade pelos colaboradores, prejudicando a concretização de ações sustentáveis, levando em conta as três dimensões (econômica, ambiental e social), já que o desafio para ter organizações sustentáveis é ter pessoas com pensamentos e atitudes sustentáveis. Jabbour, Santos, e Jabbour (2009) corroboram quando colocam que para desenvolver produtos sustentáveis precisam selecionar pessoas preparadas e articular equipes comprometidas com o desenvolvimento sustentável e com consciência ambiental.

Em pesquisa realizada por Tódero, Macke, e Biasuz (2011), as pessoas ainda não praticam a sustentabilidade. Os comportamentos de consumo sustentável que obtiveram os melhores

Revista de Gestão e Secretariado - GeSec, São Paulo, v. 4, n. 3, p 189-209, dez. 2013. 
As competências do profissional de secretariado na implantação de projetos sustentáveis

desempenhos na pesquisa foram pequenas atitudes como "evito deixar lâmpadas acesas em ambiente desocupados" e "desligo aparelhos eletrônicos quando não estou usando".

A era da sustentabilidade e das organizações sustentáveis tem um modelo orgânico, holístico e sistêmico, onde não se pode levar em conta apenas o sucesso econômico, mas também as dimensões sociais e ambientais. A sustentabilidade busca ainda, uma postura preventiva, de modo a elevar os aspectos positivos e diminuir os impactos e os efeitos negativos de qualquer empreendimento (Leal, 2009).

Segundo Oliveira et al. (2011) para aumentar a competitividade, as empresas precisarão mudar as forma de desenvolver seus produtos e serviços e identificar competências voltadas ao desenvolvimento, minimizando a agressão ao meio ambiente. Em relação as conclusões do Relatório Brundtland (WCED, 1987), em busca do desenvolvimento sustentável, está a de que todas as profissões precisam se ajustar a uma abordagem holística e integrada, pois as organizações mudam, quando as pessoas mudam.

Dessa forma, os desafios que acompanham a sustentabilidade organizacional demandam pessoas preparadas e sensíveis ao tema, que busquem em seus projetos a sustentabilidade econômica visando vantagem competitiva, qualidade e custo, foco, mercado, resultado e estratégia de negócio, a sustentabilidade ambiental por meio de tecnologias limpas, reciclagem, utilização sustentável dos recursos, atendimento a legislação, tratamento de efluentes e resíduos, utilização de produtos ecologicamente corretos e preocupados com os impactos ambientais e a sustentabilidade social, assumindo a responsabilidade social, dando suporte no crescimento a comunidade, compromisso com o desenvolvimento dos Recursos Humanos (Pereira, 2011).

Para Munck (2013) há três principais componentes da sustentabilidade organizacional que devem ser gerenciados: a ecoeficiência - fornecimento de bens e serviços a preços competitivos, reduzindo progressivamente os impactos ambientais $=$ desenvolvimento econômico $\mathrm{x}$ desenvolvimento ambiental, a inserção socioeconômica - capacidade da organização de promover mais justiça e igualdade, com crescimento dos funcionários, eliminando gradativamente os déficits sociais = desenvolvimento social x desenvolvimento econômico e a justiça socioambiental capacidade organizacional de equalizar a distribuição dos benefícios = desenvolvimento ambiental $\mathrm{x}$ desenvolvimento social. 


\title{
2.3 COMPETÊNCIAS DO PROFISSIONAL DE SECRETARIADO
}

São muitos os conceitos de competências definidos por autores como Le Boterf (1994); Durand (1998), Fleury, e Fleury (2001); que são embasados pelo CHA-Conhecimento, Habilidade e Atitudes.

Segundo Soares e França (2013) as competências para a sustentabilidade são: atenção a todos os stakeholders, empreendedorismo e inovação, foco em melhoria contínua, foco nas pessoas, liderança sustentável, prontidão para mudança, respeito a biodiversidade, valorização do diálogo, visão cooperativa, de longo prazo, sistêmica, social e comunitária.

\begin{abstract}
As competências organizacionais constituem características valorosas que as qualificam como uma alternativa consistente para o alcance da sustentabilidade nas organizações e de um desenvolvimento sustentável [...] pautado por um domínio organizacional ético e aplicado por orientações interessadas em um bem estar coletivo, a competência auxiliará a organização a comprovar sua sustentabilidade (Munck, 2013, p. 66).
\end{abstract}

A profissão de secretariado, regulamentada pelas Leis 7377/85 e 9261/96, tem suas competências definidas pelas Diretrizes Curriculares Nacionais (CNE, 2005):

\begin{abstract}
Art. $4^{\circ} \mathrm{O}$ curso de graduação em Secretariado Executivo deve possibilitar a formação profissional que revele, pelo menos, as seguintes competências e habilidades: I - capacidade de articulação de acordo com os níveis de competências fixadas pelas organizações; II visão generalista da organização e das peculiares relações hierárquicas e intersetoriais; III exercício de funções gerenciais, com sólido domínio sobre planejamento, organização, controle e direção; IV - utilização do raciocínio lógico, crítico e analítico, operando com valores e estabelecendo relações formais e causais entre fenômenos e situações organizacionais; V - habilidade de lidar com modelos inovadores de gestão; VI - domínio dos recursos de expressão e de comunicação compatíveis com o exercício profissional, inclusive nos processos de negociação e nas comunicações interpessoais ou intergrupais; VII - receptividade e liderança para o trabalho em equipe, na busca da sinergia; VIII adoção de meios alternativos relacionados com a melhoria da qualidade e da produtividade dos serviços, identificando necessidades e equacionando soluções; IX - gerenciamento de informações, assegurando uniformidade e referencial para diferentes usuários; X - gestão e assessoria administrativa com base em objetivos e metas departamentais e empresariais; XI - capacidade de maximização e otimização dos recursos tecnológicos; XII - eficaz utilização de técnicas secretariais, com renovadas tecnologias, imprimindo segurança, credibilidade e fidelidade no fluxo de informações; e XIII - iniciativa, criatividade, determinação, vontade de aprender, abertura às mudanças, consciência das implicações e responsabilidades éticas do seu exercício profissional (CNE, 2005).
\end{abstract}

Torquato (1991) anteviu que o profissional de secretariado assumiria mais responsabilidades na administração dos seus respectivos departamentos. Segundo Reich (2004) o secretário faz parte do grupo de profissionais que desempenham tarefas analítico-simbólica, que têm condições de 
As competências do profissional de secretariado na implantação de projetos sustentáveis

abstração, raciocínio sistêmico, identificam problemas e promovem soluções, bem como acompanham e controlam o processo com o objetivo de reestruturar quando necessário. Para Bruno (2006) o profissional de secretariado tem poder para influenciar nos níveis operacionais e táticos, dependendo mais de sua competência do que do nível hierárquico de seu superior.

A organização e seus executivos, já sabem da importância do profissional de secretariado, para se destacarem em seus mercados de atuação, pois sabem que este profissional "dará apoio para a empresa em todos os seus campos, auxiliando os executivos de maneira planejada e organizada, atuando em conjunto, nos assuntos estratégicos e de gestão da organização" (Martins, Terra, Maccari, \& Vicente, 2010, p. 74).

Para Aguero (2012) o secretário é um profissional sustentável, pois é um agente de mudança sistêmica em comportamento e visão de sua liderança, descontrói preconceitos, traz mudanças permanentes, considerando cada atividade de trabalho como possibilidade, aprendizagem, crescimento e é direcionado para objetivos projetados ainda não concebidos.

Para análise das competências do profissional de Secretariado na implantação de projetos sustentáveis é importante considerar a consolidação do gerenciamento em projetos nas organizações, as três dimensões da sustentabilidade e o apoio que este profissional oferece as organizações.

\section{METODOLOGIA}

O presente estudo caracteriza-se por uma pesquisa qualitativa e exploratória. A pesquisa qualitativa permite lidar com a complexidade de determinado problema, de modo a identificar e compreender processos dinâmicos vividos por grupos sociais, ampliando e aprofundando o entendimento de particularidades comportamentais (Martins \& Theóphilo, 2009). A presente pesquisa constituiu-se em um levantamento de campo, com coleta de dados, por meio da aplicação de um questionário para a identificação das competências do profissional de secretariado na implantação de projetos sustentáveis.

$\mathrm{O}$ instrumento de coleta de dados (questionário) foi desenvolvido a partir do referencial teórico e encaminhado por email para dois mil associados do Sindicato das Secretárias e Secretários do Estado de São Paulo-SINSESP.

A amostra respondente integrou 206 profissionais de secretariado, sendo 99\% do sexo feminino, $70 \%$ com curso superior completo (sendo $40 \%$ em Secretariado), $4 \%$ com superior 
incompleto e $26 \%$ com cursos técnicos. Já $65 \%$ possuem o registro profissional como Secretária(o) na Superintendência Regional do Trabalho e Emprego (SRTE), órgão do Ministério do Trabalho.

Ao fazer a análise dos dados da pesquisa, este trabalho pretende considerar as seguintes variáveis: quais são os projetos sustentáveis que o profissional de secretariado está inserido e analisar o envolvimento do profissional de secretariado na implantação de projetos sustentáveis, segundo as áreas do conhecimento de gestão de projetos, para atender o objetivo proposto de identificar as competências do profissional de secretariado na implantação de projetos sustentáveis.

\subsection{PROPOSIÇÃO DE PESQUISA}

A partir da revisão bibliográfica foi possível formular proposições, conforme Quadro 2, para elaboração de um questionário, encaminhado por e-mail para dois mil associados do Sindicato das Secretárias e Secretários do Estado de São Paulo.

\begin{tabular}{|c|c|c|}
\hline PROPOSIÇÃO & FONTE & QUESTÃO \\
\hline $\begin{array}{l}\text { P1. Uma visão mais ampla de } \\
\text { sustentabilidade emergiu recentemente, } \\
\text { uma perspectiva tridimensional, } \\
\text { incorporando as dimensões econômica, } \\
\text { social e ambiental. }\end{array}$ & $\begin{array}{l}\text { Elkington } \\
\text { (2001). }\end{array}$ & 1. O que é sustentabilidade para você? \\
\hline $\begin{array}{l}\text { P2. O Guia do Conhecimento em } \\
\text { Gerenciamento de Projetos é referência } \\
\text { básica para o gerenciamento de projetos. } \\
\text { Nele encontramos as nove áreas do } \\
\text { conhecimento, que agrupam atividades e } \\
\text { tarefas. }\end{array}$ & PMI, 2008 & $\begin{array}{l}\text { 2. Sua empresa adota as práticas do } \\
\text { Gerenciamento de Projetos com base no } \\
\text { PMBOK? }\end{array}$ \\
\hline $\begin{array}{l}\text { P3. O profissional de Secretariado tem } \\
\text { suas competências definidas pelas } \\
\text { Diretrizes Curriculares Nacionais }\end{array}$ & CNE, 2005 & $\begin{array}{l}\text { 3. Quais as competências do } \\
\text { profissional de Secretariado? }\end{array}$ \\
\hline $\begin{array}{l}\text { P4. As competências para a } \\
\text { sustentabilidade são: atenção a todos os } \\
\text { stakeholders, empreendedorismo e } \\
\text { inovação, foco em melhoria contínua, foco } \\
\text { nas pessoas, liderança sustentável, } \\
\text { prontidão para mudança, respeito a } \\
\text { biodiversidade, valorização do diálogo, } \\
\text { visão cooperativa, de longo prazo, } \\
\text { sistêmica, social e comunitária. }\end{array}$ & $\begin{array}{l}\text { Soares e França } \\
\text { (2013) }\end{array}$ & $\begin{array}{l}\text { 4. Quais competências do profissional } \\
\text { de secretariado podem contribuir na } \\
\text { implantação de projetos sustentáveis? }\end{array}$ \\
\hline
\end{tabular}

Quadro 2 - Preposições e questões de pesquisa.

Fonte: Elaborado pelos autores. 
As competências do profissional de secretariado na implantação de projetos sustentáveis

\section{ANÁLISE DE RESULTADOS}

Dos 2.000 questionários enviados, obteve-se um retorno de 10\% (206), dos quais $99 \%$ dos respondentes são do sexo feminino, sendo que $45 \%$ são formados em Secretariado e $65 \%$ possuem registro de Secretária no órgão responsável - Superintendência Regional de Trabalho e Emprego (SRTE). Observou-se que 70\% dos respondentes residem na cidade de São Paulo.

Por meio da Tabela 1 constata-se que 53\% dos respondentes trabalham em empresas de grande porte, $25 \%$ em empresas de médio porte e $17 \%$ de pequeno porte. São $79 \%$ que trabalham em empresas nacionais, $17 \%$ em empresas internacionais. Sobre o tipo de empresa, 69\% são de empresas privadas; $17 \%$ de empresas públicas e $8 \%$ de empresas de economia mista. Dos respondentes, $57 \%$ assessoram a Diretoria, $23 \%$ a Presidência e $20 \%$ a Gerência. Diante dos resultados apresentados observa-se que a pesquisa abrangeu vários tipos e portes de empresas e que o levantamento ficou bem distribuído entre todas estas empresas.

Tabela 1 - Dados da Empresa do respondente

\begin{tabular}{|l|c|l|l|l|l|l|c|}
\hline \multicolumn{2}{|c|}{ PORTE DA EMPRESA } & \multicolumn{2}{|c|}{ PROCEDÊNCIA } & \multicolumn{2}{c|}{ TIPO } & \multicolumn{2}{c|}{$\begin{array}{c}\text { DEPTO. ONDE } \\
\text { TRABALHAM }\end{array}$} \\
\hline Grande & $53 \%$ & Nacional & $79 \%$ & Privado & $69 \%$ & Diretoria & $57 \%$ \\
\hline Médio & $25 \%$ & Internacional & $17 \%$ & Público & $17 \%$ & Presidência & $23 \%$ \\
\hline Pequeno & $17 \%$ & N. Respond. & $4 \%$ & Misto & $8 \%$ & Gerência & $20 \%$ \\
\hline N. Respond. & $5 \%$ & & & N. Respond. & $6 \%$ & & \\
\hline
\end{tabular}

Fonte: Elaborado pelos autores.

Na Figura 1, constata-se que o profissional de Secretariado se concentra em empresas do ramo de serviços $(38 \%)$ e indústria $(25 \%)$.

A Figura 2 apresenta o entendimento que os respondentes têm sobre o termo sustentabilidade. Dos respondentes, 51\% definem como "capacidade do ser humano interagir com o mundo, preservando o meio ambiente para não comprometer os recursos naturais das gerações futuras" e "equilíbrio entre as dimensões ambiental, social e econômica." São 30\% aqueles que

Revista de Gestão e Secretariado - GeSec, São Paulo, v. 4, n. 3, p 189-209, dez. 2013. 
definem apenas como "capacidade do ser humano interagir com o mundo, preservando o meio ambiente para não comprometer os recursos naturais das gerações futuras" e $17 \%$ apenas como o “equilíbrio entre as dimensões ambiental, social e econômica". Este resultado mostra que a maioria dos profissionais de secretariado tem um bom entendimento do conceito de sustentabilidade, não havendo deficiência no entendimento, conforme preocupação apresentada por Claro, Claro, e Amâncio (2008).

Figura 1 - Ramo da Empresa

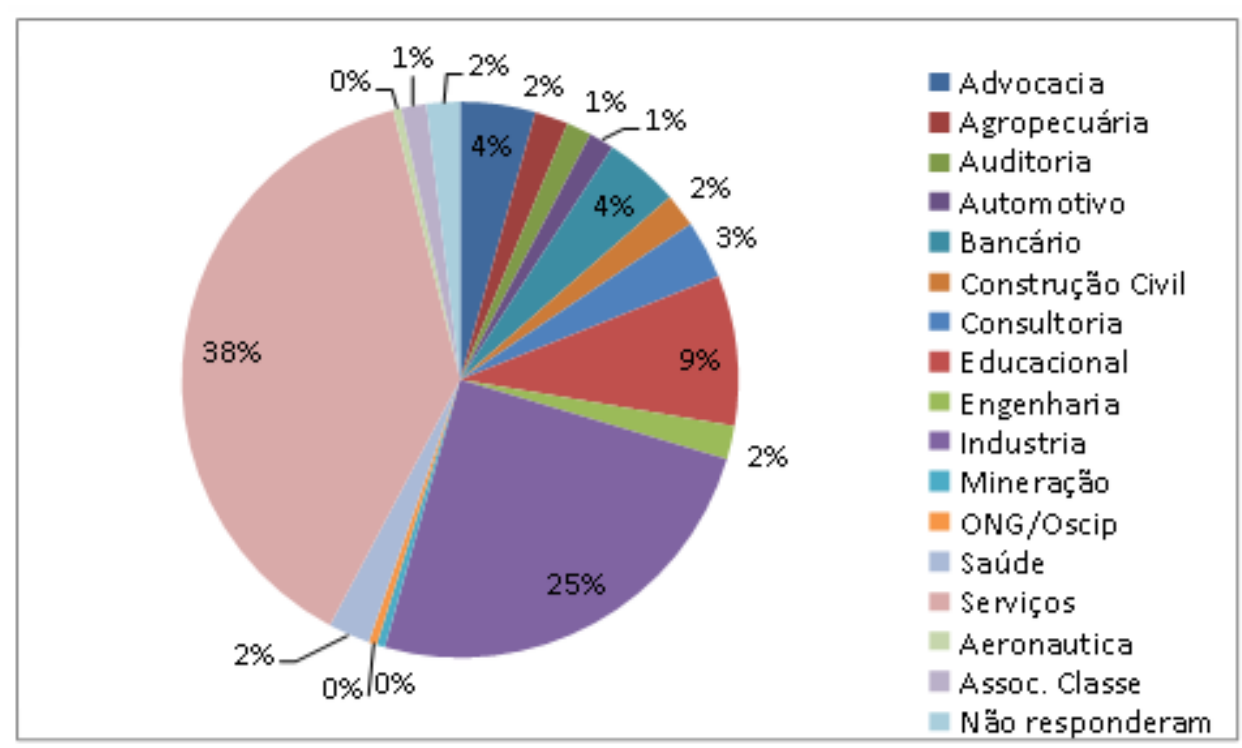

Fonte: Elaborado pelos autores.

Figura 2 - Definição para sustentabilidade.

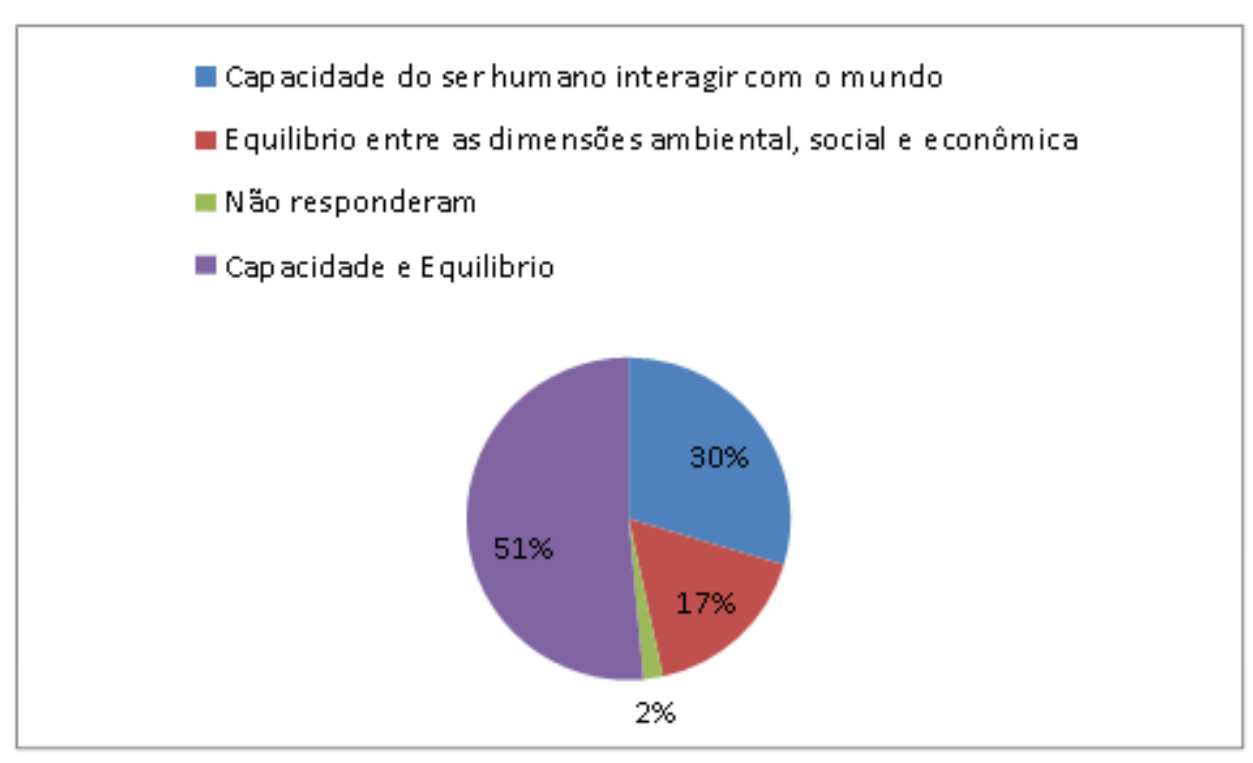

Fonte: Elaborado pelos autores.

Revista de Gestão e Secretariado - GeSec, São Paulo, v. 4, n. 3, p 189-209, dez. 2013. 
As competências do profissional de secretariado na implantação de projetos sustentáveis

Dos entrevistados, 58\% já participaram de algum tipo de palestra/treinamento sobre sustentabilidade. Já $38 \%$ trabalham em empresas que adotam as práticas do Gerenciamento de Projetos com base no PMBOK, conforme Figura 3. Isto demonstra um conhecimento dos profissionais de secretariado, em relação ao tema sustentabilidade, gerando comprometimento com o desenvolvimento sustentável, conforme necessidade apresentada por Jabbour, Santos, e Jabbour (2009) em selecionar pessoas preparadas e articular equipes comprometidas com o desenvolvimento sustentável e com consciência ambiental.

Figura 3 - Empresas que adotam o PMBOK no gerenciamento de projetos.

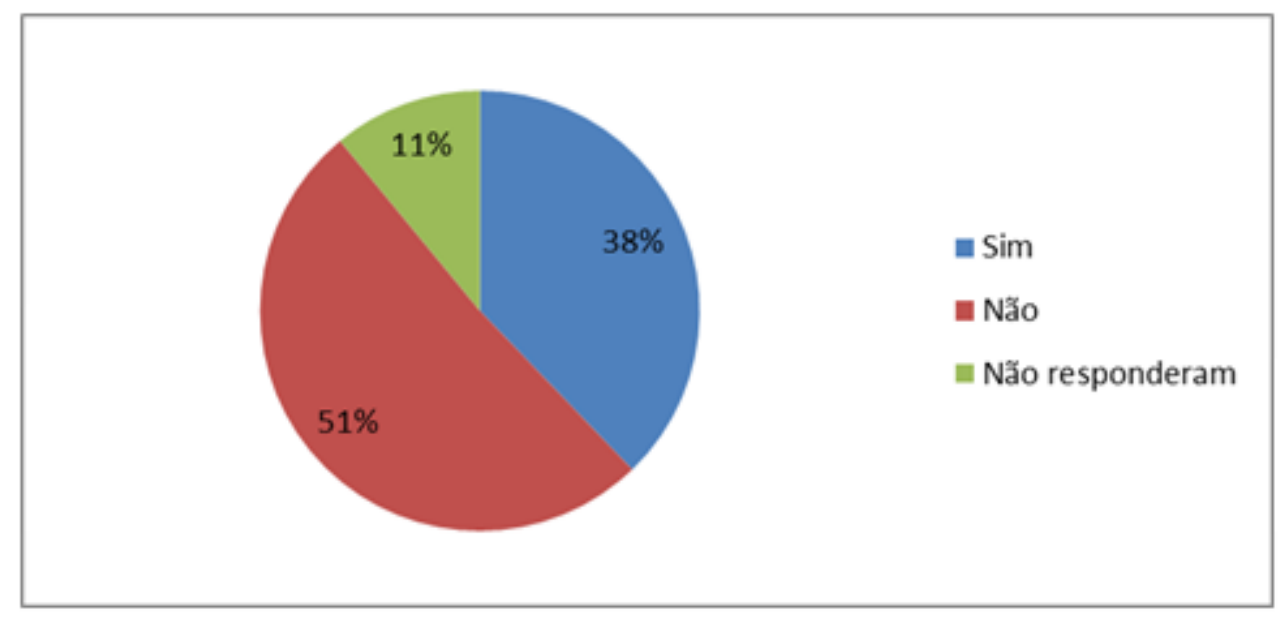

Fonte: Elaborado pelos autores.

Das empresas dos respondentes, 59\% implantaram ou estão implantando algum projeto de sustentabilidade. Em 56\% dos casos, projetos de reciclagem, conforme Figura 4. E 77\% dos profissionais de secretariado, das empresas que já implantaram ou estão implantando algum projeto de sustentabilidade, estão envolvidos na implantação destes projetos.

Estão envolvidos diretamente na implantação dos projetos de sustentabilidade $26 \%$ dos respondentes. Já $20 \%$ estão envolvidos no assessoramento à equipe do projeto. Seguindo o PMBOK, 5\% estão envolvidos na comunicação e $1 \%$ na qualidade, conforme Figura 5. Esses números mostram que o profissional de Secretariado pratica a sustentabilidade, ao contrário da pesquisa de Tódero, Macke, e Biasuz (2011), em que o resultado apontou que as pessoas ainda não praticam a sustentabilidade.

Apesar do grande número de profissionais de secretariado envolvidos em projetos de sustentabilidade, $48 \%$ dos profissionais, não responderam qual é o seu papel, impossibilitando 
maior análise das competências do profissional de Secretariado na implantação de projetos sustentáveis.

Figura 4 - Tipos de projetos de sustentabilidade.

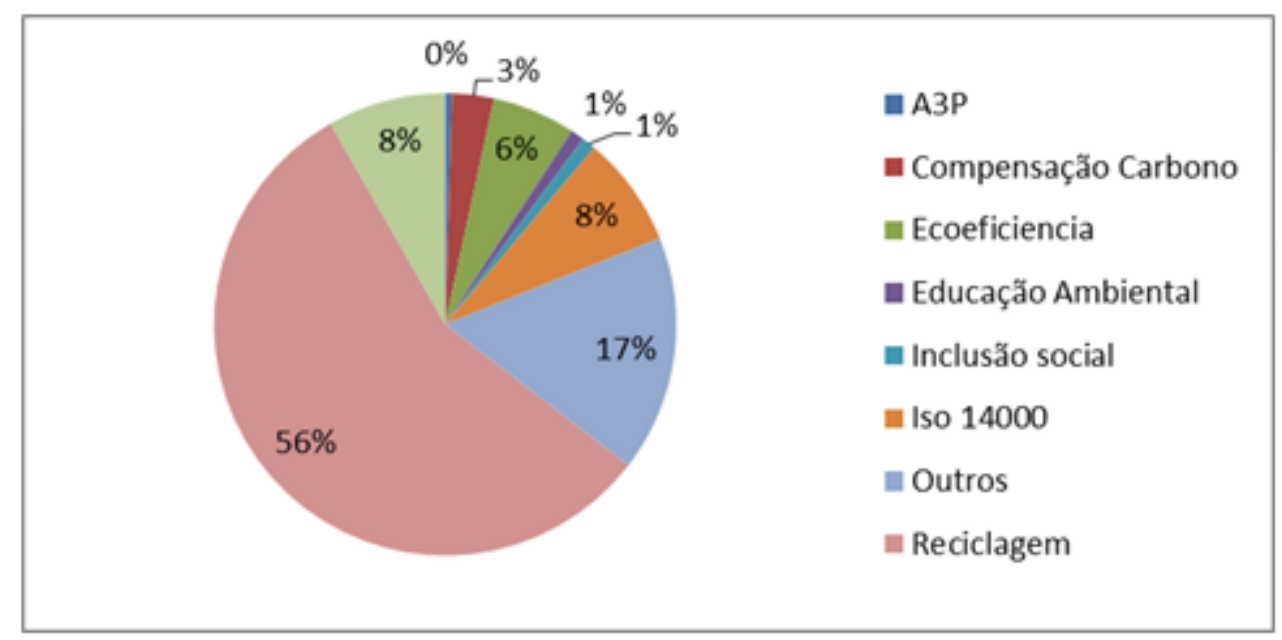

Fonte: Elaborado pelos autores.

Figura 5 - Envolvimento com o Projeto.

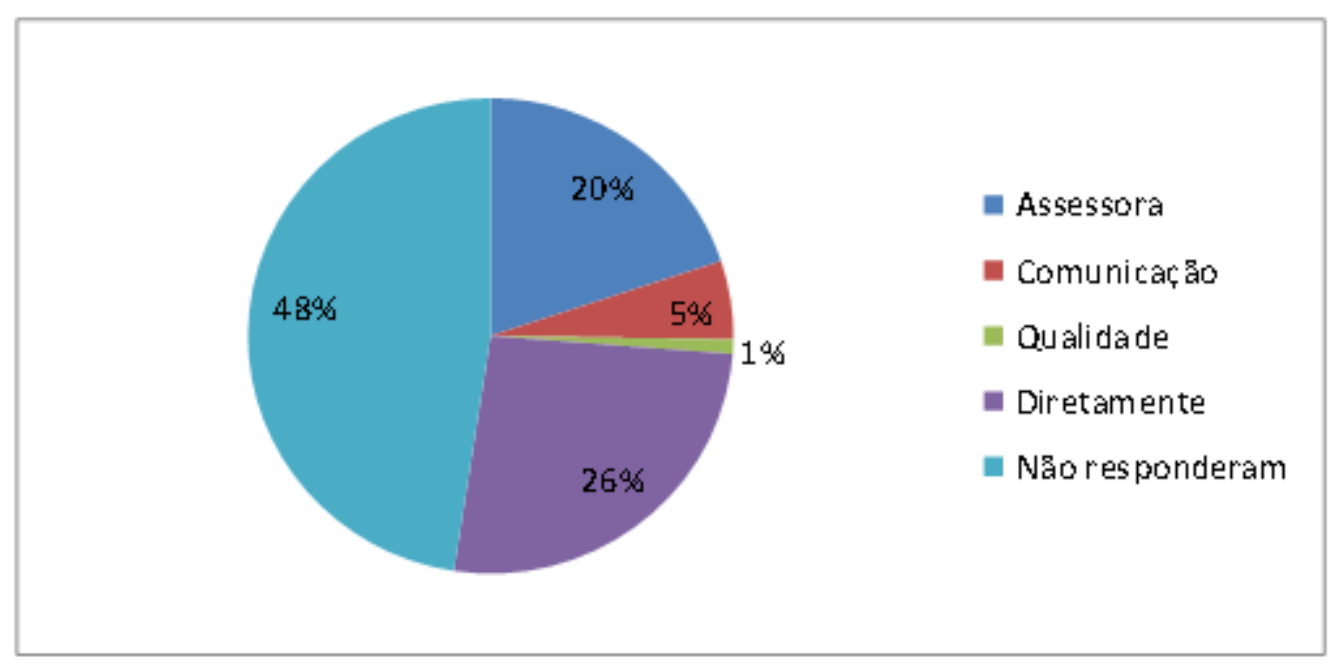

Fonte: Elaborado pelos autores.

Dentre as competências do profissional de secretariado que contribuem na implantação de projetos sustentáveis, a Tabela 4 apresenta o resultado das competências apresentadas pelos 206 respondentes que são compatíveis com as competências da sustentabilidade (Soares \& França, 2013). Destaca-se o “domínio dos recursos de expressão e de comunicação, inclusive nos processos

Revista de Gestão e Secretariado - GeSec, São Paulo, v. 4, n. 3, p 189-209, dez. 2013. 
de negociação e nas comunicações interpessoais ou intergrupais e a capacidade de articulação" que segundo $82 \%$ dos respondentes pode contribuir na implantação de projetos sustentáveis, confirmando a contribuição do profissional de secretariado no sucesso da comunicação dos projetos sustentáveis.

Tabela 4 - Competências para a Sustentabilidade x Secretariado

\begin{tabular}{|c|c|c|}
\hline $\begin{array}{l}\text { COMPETÊNCIAS PARA A } \\
\text { SUSTENTABILIDADE } \\
\text { (SOARES E FRANÇA, 2013) }\end{array}$ & $\begin{array}{c}\text { COMPETENNCIAS DO PROFISSIONAL DE } \\
\text { SECRETARIADO }\end{array}$ & RESPONDENTES \\
\hline Atenção a todos os stakeholders. & $\begin{array}{l}\text { Gerenciamento de informações, assegurando } \\
\text { uniformidade e referencial para diferentes usuários. }\end{array}$ & $73 \%$ \\
\hline Empreendedorismo e inovação. & $\begin{array}{l}\text { Habilidade de lidar com modelos inovadores de gestão e } \\
\text { exercício de funções gerenciais. }\end{array}$ & $56 \%$ \\
\hline $\begin{array}{l}\text { Foco em melhoria contínua e nas } \\
\text { pessoas. }\end{array}$ & $\begin{array}{l}\text { Adoção de meios alternativos relacionados com a } \\
\text { melhoria da qualidade e da produtividade dos serviços. }\end{array}$ & $76 \%$ \\
\hline Prontidão para mudança. & $\begin{array}{l}\text { Abertura às mudanças, iniciativa, criatividade, } \\
\text { determinação, vontade de aprender. }\end{array}$ & $72 \%$ \\
\hline Respeito à biodiversidade. & $\begin{array}{l}\text { Consciência das implicações e responsabilidades éticas e } \\
\text { utilização do raciocínio lógico, crítico e analítico. }\end{array}$ & $72 \%$ \\
\hline $\begin{array}{l}\text { Valorização do diálogo } \\
\text { visão cooperativa, de longo } \\
\text { prazo, sistêmica, social e } \\
\text { comunitária. }\end{array}$ & $\begin{array}{l}\text { Domínio dos recursos de expressão e de comunicação, } \\
\text { inclusive nos processos de negociação e nas } \\
\text { comunicações interpessoais ou intergrupais, capacidade } \\
\text { de articulação. }\end{array}$ & $82 \%$ \\
\hline
\end{tabular}

Fonte: Elaborado pelos autores.

Sobre como as empresas poderiam envolver mais o profissional de Secretariado na implantação de projetos sustentáveis, segundo estes profissionais obtiveram-se incentivo e orientação ao profissional, por meio de capacitação, treinamento e delegação de mais atribuições dentro do projeto. 


\section{CONSIDERAÇÕES FINAIS}

Este artigo se propôs a identificar as competências do profissional de Secretariado na implantação de projetos sustentáveis, pesquisando em quais projetos sustentáveis o profissional de secretariado está inserido e analisando o seu envolvimento nesses projetos, segundo as áreas do conhecimento (PMI, 2008).

O relatório do RobecoSAM (2013), que coloca o Brasil em 45․ lugar no ranking de sustentabilidade, mostra que as organizações brasileiras ainda necessitam desenvolver uma consciência mais madura em sustentabilidade e apresentar um estágio maior de responsabilidade e gestão socioambiental.

Os dados do questionário apontam que mais de 50\% dos profissionais de secretariado, conhecem o conceito geral da sustentabilidade: "capacidade do ser humano interagir com o mundo, preservando o meio ambiente para não comprometer os recursos naturais das gerações futuras" (WCED, 1987) e o equilíbrio entre as dimensões ambiental, social e econômica (Elkington, 2001), mostrando consciência do tema sustentabilidade.

$\mathrm{Na}$ avaliação dos projetos sustentáveis que o profissional de secretariado está inserido, mais de 50\% são de projetos de reciclagem e a outra metade se divide entre projetos de ecoeficiência e inclusão social, entre outros, que nos mostra que, além de haver comprometimento com a sustentabilidade, há um equilíbrio entre as três dimensões: ambiental, social e econômica.

O profissional de secretariado está pouco envolvido com as áreas do conhecimento do PMBOK, apresentando um pequeno envolvimento na área das comunicações e outro menor na área da qualidade. Para melhorar este envolvimento o profissional de Secretariado espera das empresas mais incentivo, orientação, capacitação, treinamento e delegação de mais atribuições na implantação de projetos sustentáveis.

São várias as competências do profissional de secretariado apresentadas para contribuir na implantação de projetos sustentáveis. Relacionando com as competências para a sustentabilidade (Soares \& França, 2013), destaca-se adoção de meios alternativos relacionados com a melhoria da qualidade e da produtividade dos serviços; domínio dos recursos de expressão e de comunicação compatíveis com o exercício profissional, inclusive nos processos de negociação e nas comunicações interpessoais ou inter-grupais; gerenciamento de informações, assegurando uniformidade e referencial para diferentes usuários; habilidade de lidar com modelos inovadores de gestão; iniciativa, criatividade, determinação, vontade de aprender, abertura às mudanças, 
As competências do profissional de secretariado na implantação de projetos sustentáveis

consciência das implicações e responsabilidades éticas e utilização do raciocínio lógico, crítico e analítico.

A limitação deste estudo está no grande número de profissionais que não responderam qual o envolvimento na implantação do projeto e o fato de a pesquisa ter sido feita apenas com profissionais do estado de São Paulo. Para futuros estudos recomendam-se pesquisas com profissionais de secretariado de outros estados e verificação da relação entre o porte e ramo de atividade da empresa e a quantidade de projetos sustentáveis desenvolvidos pelos profissionais de secretariado, para se levantar em que porte de empresa e ramo de atividade o papel deste profissional na implantação de projetos sustentáveis é mais importante.

\section{REFERÊNCIAS}

Adelino, F. J. \& Silva, M. A. V. (2012). A tecnologia da informação como agente de mudança no perfil do profissional de secretariado. Revista de Gestão e Secretariado, 3(2), 05-23.

Aguero, C. F. R. (2012). La secretaria sustentable. Posadas: Creativa.

Barbieri, J. C. (2010). Gestão ambiental empresarial: conceitos, modelos e instrumentos. São Paulo: Saraiva.

Barbieri, J. C.; Vasconcelos, I. F.; Andreassi, T. \& Vasconcelos, F. (2010). Inovação e sustentabilidade: novos modelos e proposições. Revista de Administração de Empresas (RAE), vol. 50, n. 2.

Brito, R. P. \& Berardi, P. C. (jun/2010). Vantagem competitiva na gestão sustentável da cadeia de suprimentos: Um metaestudo. Revista Administração de Empresas, São Paulo, vol. 50, n. 2.

Bruno, I. M. (2006). O poder de influência do profissional de secretariado no processo decisório das organizações. Dissertação de mestrado em Administração de Empresas. Pontifícia Universidade Católica, São Paulo.

Carvalho, M. M. \& Rabechini Jr, R. (2006). Construindo competências para gerenciar projetos: teorias e casos. São Paulo: Atlas.

R. (2011). Fundamentos em gestão de projetos - Construindo competências para gerenciar projetos. São Paulo: Atlas.

Revista de Gestão e Secretariado - GeSec, São Paulo, v. 4, n. 3, p 189-209, dez. 2013. 
Claro, P. B. O: Claro, D. P., \& Amâncio, R. (outubro-dezembro, 2008). Entendendo o conceito de sustentabilidade nas organizações. Revista de Administração - RAUSP, vol. 43, núm. 4, pp. 289300.

CNE-Conselho Nacional de Educação. Câmara de Educação Superior. (2005). Resolução CNE/CES N. 4, de 23 de junho de 2005. Institui as Diretrizes Curriculares Nacionais do curso de graduação em Secretariado Executivo. Brasília: Diário Oficial da República Federativa da União. Seção 1, p. 79, 14 de julho de 2005 .

Durand, T. (1998). Forms of incompetence. I: Fourth International Conference on Competence, Based Management. Osb: Norwegian School of Management.

Elkington, J. (2001). Canibais com garfo e faca. São Paulo: M. Books.

Fleury, M. T. L. \& Fleury, A. (2001). Construindo o conceito de competência. Rev. Administração Contemporânea, Curitiba, vol. 5, n. spe.

Frame, J.D. (1999) Project management competence: building key skills for individuals, teams and organizations. São Francisco: Jossey-Bass.

Halice, A.; Yilmaz, B. \& Kasimoğlu, M. (2012). Employment Preedictions in Secretarial Occupation. Journal of Management and Sustainability. (Vol. 2., no. 2.)

Jabbour, C. J. C.: Santos, F. C. A., \& Jabbour, A. B. L. de S. (2009). A importância dos fatores humanos no desenvolvimento de produtos com elevado desempenho ambiental: estudo de casos. Revista de Administração Mackenzie - RAM, 10(4), 32-56.

Kerzner, H. (2006). Gestão de projetos: as melhores práticas. (2a ed.) Porto Alegre: Bookman.

(2011). Gerenciamento de projetos. Uma abordagem sistêmica para planejamento, programação e controle. São Paulo: Blucher.

Leal, C.E. (2009). A era das organizações sustentáveis. Revista Eletrônica Novo Enfoque da Universidade Castelo Branco, Vol. 8 (n.8).

Le Boterf. G. (1994). De la compétence: essai sur un attracteur étrange. Paris: Éditions d'Organizations.

Lei 7.377/85 e Lei 9.261/96. Recuperadas em 10 set. 2013 de http://www.sinsesp.com.br/index.php/secretariasos/70/271-lei7377. Acesso em 10/09/2013. 
As competências do profissional de secretariado na implantação de projetos sustentáveis

Martens, M. L.; Brones, F. \& Carvalho, M. M. (jan./abr. 2013). Lacunas e tendências na literatura de sustentabilidade no gerenciamento de projetos: uma revisão sistemática mesclando bibliometria e análise de conteúdo. Revista de Gestão e Projetos - GeP, São Paulo, vol. 4, n. 1, pp. 165-195.

Martins, C. B., Terra, P. M., Maccari, E. A., \& Vicente, I. (2010). A formação do profissional em secretariado executivo no mercado de trabalho globalizado. Revista de Gestão e Secretariado, $1(1), 69-89$.

Martins, G.A. \& Theóphilo, C. R. (2009). Metodologia da investigação científica para ciências sociais aplicadas. São Paulo: Atlas.

Maximiano, A. C. A. (2002). Administração de projetos. São Paulo: Atlas.

Munck, L. \& Borim-de-Souza, R. B. B. (2009). Gestão por competências e sustentabilidade empresarial: em busca de um quadro de análise. Gestão e Sociedade, vol. 3, n. 6, pp. 254-287.

Munck, L. (2013). Gestão da sustentabilidade nas organizações - Um novo agir frente à lógica das competências. São Paulo: Cengage Learning.

Oliveira, A.C. et al. (2011). Alinhamento da estratégia para a sustentabilidade competências essenciais: uma revisão bibliográfica. Ponta Grossa: Combrepo.

Pereira, A. C. (2011). Sustentabilidade na prática: fundamentos, experiências e habilidades. Valinhos-SP: Anhanguera Publicações.

PMI (2008). A guide to the project management body of knowledge - PMbok - Project Management Institute.

Reich, R. (1994). O trabalho das nações. São Paulo: Educator.

RobecoSAM (2013). Measuring Country Intangibles. RobecoSAM's Country Sustainability Ranking.

Shenhar, A. J., \& Dvir, D. (2010). Reinventando Gerenciamento de Projetos. São Paulo: M. Books.

Soares, F.H. \& França, S. L. B (2013). Competências para a sustentabilidade: uma contribuição para o desenvolvimento de pessoas no tema em questão. $9^{\circ}$. Congresso Nacional de Excelência em Gestão. Rio de Janeiro.

Souza, M. T. S. (1993). Rumo à prática empresarial sustentável. RAE. Revista de Administração de Empresas, São Paulo, vol. 33, n. 4, pp. 40-52. 
Souza, R. B. $O$ alinhamento entre sustentabilidade e competências em contexto organizacional. (2010). Dissertação (Mestrado em Administração) - Programa de Pós-graduação em Administração, Universidade Estadual de Maringá (UEM) / Universidade Estadual de Londrina (UEL), Londrina.

Thamhain, H. J. (mai./ago. 2012). The Changing Role of Team Leadership in Multinational Project Environments. Revista de Gestão e Projetos - GeP, São Paulo, vol. 3, n. 2, pp. 04-38.

Tódero, M.: Macke, J. \& Biasuz, T. S. (2011). O consumo consciente e a relação com as ações de responsabilidade social empresarial. Revista de Gestão Social e Ambiental, 5(1). doi:10.5773/rgsa.v5i1.284

Torquato, G. (1991). Cultura, poder, comunicação e imagem. São Paulo: Pioneira.

Valle, A. B., Soares, P. C. A., Finocchio, J. Jr., \& Silva L. S. F. (2007). Fundamentos do gerenciamento de projetos. Rio de Janeiro: FGV.

WCED. Our Common future: The Brundtland Report. Oxford: Oxford University Press, 1987. 